\title{
BENTUK ESTETIK ONDEL-ONDEL
}

\author{
Supriyanto \\ Program Pascasarjana \\ Institut Seni Indonesia Surakarta \\ Jl. Ki Hadjar Dewantara No. 19 Kentingan, Jebres, Surakarta, 57126
}

Dharsono

ISI Surakarta

\begin{abstract}
ABSTRAK
Studi tentang keberadaan Ondel-ondel di Jakarta sebagai sajian dan fungsi Ondel-ondel. Penelitian ini menjelaskan bentuk dan pemaknaan Ondel-ondel dikaji dengan pendekatan estetik digunakan teori De Witt $\mathrm{H}$. Parker. Pembahas masalah tersebut menggunakan metode penelitian kualitatif. Analisis data menggunakan interaksi analisis dan interprestasi analisis tekstual. Keberadaan Ondel-ondel di Jakarta berdasarkan dari latar belakang sejarah Ondel-onde/sebelumnya bernama Barongan setelah mendapatkan kembang kelapa (ronceronce) yang terbuat dari kertas nama Barongan diganti dengan Ondel-ondel. Barongan di yakini masyarakat Betawi memiliki kekuatan magis berkarakter seram berfungsi sebagai penolak mara bahaya (sedekah desa atau sedekah bumi) dan peresmian gedung pada masa lalu. Tetapi sekarang Ondel-ondel dengan bentuknya yang ramah berfungsi sebagai hiburan seremonial dan dekorasi untuk tujuan estetis.
\end{abstract}

Kata kunci: Ondel-Ondel, Estetik.

\begin{abstract}
It is a study on the existence of Ondel-ondel in Jakarta as an entertainment and a function of Ondel-ondel. This research tells about the form and meaning of Ondel-ondel. It is analyzed through aesthetic approach of De Witt H. Parker's theory and uses qualitative method. Data is analyzed by using interaction analysis and textual analysis interpretation. Based on the historical background of Ondel-ondel, it is previously named Barongan and after getting coconut flower (ronce-ronce) made of paper, it is changed to Ondel-ondel. People in Betawi believe that Barongan has a magic power with scary character functioning to avoid danger (offerings to village or earth)) and building inauguration in the past. But nowadays, Ondel-ondel with a kindly form becomes a ceremonial entertainment and decorations for aesthetic meaning.
\end{abstract}

Keywords: Ondel-ondel, Aesthetic.

\section{A. Pengantar}

Ondel-ondel mengacu pada sejenis seni pertunjukan rakyat yang hadir di lingkungan masyarakat Betawi. Semula Ondel-ondel dipercaya sebagai media untuk membersihkan dari hal-hal yang gaib, juga menghindari marabahaya atau pelindung (tameng). Masyarakat Betawi, secara formal hidup dan berkembang dengan fenomena-fenomena unik di kehidupan kota majemuk yang mengembangkan budayanya dengan percampuran bangsa-bangsa lain. Ondel-onde/ sebagai benda seni memiliki fungsi yang cukup penting dalam kehidupan masyarakat, walaupun dari segi praktis telah bergeser kepada fungsi non praktis sebagai hiburan dan dekorasi pada masa kini. Kemungkinan itu bisa dilihat pada fenomena-fenomena yang ada di Jakarta, kehadiran Ondel-ondelyang pal- ing menonjol dan mobilitasnya tinggi di tengah-tengah masyarakat. Kehadirannya dengan kemeriahan di acara-acara muncul dengan sendirinya sebagai branding milik masyarakat dan dikenal dekat dengan masyarakat.

Ondel-ondel sebagai pencitraan kota yang menampung bayak masyarakat sebagai bentuk bagian dari hiburan. Baik hiburan untuk keperluan masyarakat Betawi yaitu sebagai pengiring pada acara adat Betawi yaitu pernikahan dan sunatan, juga sebagai acara untuk karnaval Hari Ulang Tahun kota Jakarta. Selain itu juga sebagai benda estetis untuk menunjang keperluan dekorasi di masyarakat Betawi maupun masyarakat penggunanya.

Ada anggapan di masyarakat Betawi bahwa Ondel-ondel ini di jadikan sebagai pelengkap pada acara-acara budaya Betawi dan acara-acara 


\section{GEARR hamisanibuson}

seremonial tertentu, tetapi jika ditanya mengenai prinsip dasar makna maupun fungsi mereka tidak peduli soal hal itu. Menurut masyarakat Betawi, Ondelonde/ sebagai pelengkap dalam acara-acara tersebut dan tidak lebih dari itu. Bagi mereka kehadiran Ondelonde/ di masyarakat Betawi sudah cukup menunjukan bahwa kesenian ini adalah milik Betawi. Jika melihat fenomena di Jakarta khususnya masyarakat Betawi ternyata mereka menempatkan Ondel-ondel untuk sekedar meramai-ramaikan saja tidak lebih dari itu. Maka perlu dilakukan penelitian ini lebih mendalam tentang fungsi dan makna, agar Ondel-ondel ini bukan lagi sebagai benda artifisial di dalam kebudayaan Betawi. Tetapi bisa menjadi sebuah identitas yang penuh makna dan mengikat bahwa Betawi sebagai pemilik Ondel-ondel sekaligus menambah kekayaan khasanah budaya Nusantara.

Obyek penelitian ini berupa karya seni rupa rakyat dan untuk menelaah lebih dalam tentang kajian Ondel-ondel perlu dirumuskan sebagai berikut. (1) Bagaimana Keberadaan Ondel-ondel di Jakarta? (2) Bagaimana sajian dan fungsi Ondel-onde/ di Jakarta? (3) Bagaimana bentuk dan pemaknaanya Ondelondel?. Penelitian ini bertujuan untuk mengetahui keberadaan masyarakat Betawi menggunakan Ondelondel. Menjelaskan sajian dan fungsi Ondel-ondel untuk ditempatkan dimana dan untuk kepentingannya. Memberikan penjelasan tentang bentuk dan pemaknaanya mengenai keindahan estetik didalam Ondel-ondel. Penelitian ini diharapkan mampu memberikan manfaat yang berarti terutama untuk penulis, mahasiswa, seniman, budayawan, dan seluruh kalangan pembaca secara umum. Penelitian pada hakikatnya merupakan suatu upaya untuk menemukan kebenaran atau lebih membenarkan kebenaran (Lexy J. Maleong, 2010:49). Metode penelitian yang digunakan adalah metode kualitatif bersifat interprestasi analisis.

Analisi data bertujuan untuk proses mengorganisasikan dan mengurutkan data dalam menganalisis data yang ditemukan di lapangan. Semua data diperoleh baik melalui studi pustaka maupun studi lapangan kemudian di seleksi dan dipilih serta berorientasi pada konteksnya. Sebuah proses untuk menjelaskan fungsi dan makna digunakan deskripsi analisis dan interpretasi secara langsung dengan kacamata peneliti (tafsir). Selanjutnya dalam penelitian digunakan analisis kualitatif dikemukakan oleh lan Day 1993 dalam Lexy J. Moleong (2010:289) yaitu mendiskripiskan fenomena, mengklasifikasikan, melihat bagaimana konsep-konsep yang muncul itu satu dengan yang lain berkaitan. Data yang bersumber dari lokasi penelitian menyangkut aktivitas pembuat, pelaku, dan pengamat Ondel-ondel dan segala aspeknya.

Perkembangan aspek seni rupa pada peraga Ondel-ondel mungkin dapat dikaitakan dengan faktor ke-Islaman yang menentukan perubahan. Oleh karena itu, dapat dikatakan semua orang Betawi adalah muslim, hal ini juga disepakati oleh Amsir (2001:116) bahwa Betawi identik dengan Islam (Abdul Chaer, 2015:214). Penggambaran dalam Islam secara visual Ondel-ondel merupakan transformasi bentuk-bentuk sepasang yang distorsinya menjadi amat disengaja agar peraga-peraga itu menjadi tiruan yang naturalis dari tubuh-tubuh manusia biasa yang ada dalam kehidupan nyata (Edi Sedyawati, 2009:99).

\section{B. Keberadaan Ondel-ondel di Tanah Betawi}

Betawi adalah suku yang berasal dari hasil peranakan antar etnis dan bangsa di masa lalu. Generasi yang lahir dari pernikahan campur ini tidak lagi mengenal etnis ayah-ibunya, sehingga mereka disebut orang Betawi (Abdul Chaer, 2015:11). Keberadaan Ondel-ondel pada awalnya muncul di Betawi pinggir, namun Ondel-onde/ menjadi sebuah identitas masyarakat Betawi yang berada di Jakarta. Meskipun sejarah munculnya suku Betawi sudah sering dibahas oleh ilmuwan, tetapi masih relevan untuk memberikan gambaran terjadinya proses terbentuknya etnis masyarakat Betawi dengan pendekatan sejarah dengan sumber yang dirunut dari masa kerajaan Sunda kelapa, Jayakarta, Batavia dan Jakarta. Karena dalam kajian ini akan memperoleh dugaan atau analogi keberadaan Ondel-ondel pada waktu kemunculan hingga Ondel-ondel sekarang.

Pada tanggal 22 Juni 1527, kota bandar Sunda Kelapa jatuh ke tangan Islam dari Kerajaan Demak dibawah pimpinan Fatahillah atau Faletehan (Fadhillah Khan) bagi orang Portugis beliau dikenal dengan nama Tagaril. Sejak itu Portugis kalah dari peperangan nama Sunda Kelapa berubah menjadi Jayakarta (Tawalinuddin Haris, 2007 dalam Sukanto 1954:3). Tanggal tersebut kemudian dijadikan sebagai hari kelahiran kota Jakarta diberi nama Jayakarta yang dalam bahasa Jawa Kuno (Sansekerta) berarti 'telah membuat kemenangan' atau kesejahteraan mutlak. Maka tidak mustahil bila arti sebuah nama tersebut sekarang Jakarta sudah menunjukan suatu kemenangan dalam membangun kota menuju modernisasi.

Sejak itu nama Jayakarta atau Jaccatra ${ }^{1}$ menurut Belanda berganti menjadi Batavia. Kemudian 
Batavia berkembang menjadi kota yang besar dan penting, nama ini dipilih untuk mengenang suku bangsa atau menghormati leluhur bangsa Belanda. Sejak abad ke-16, Christopher Fryke dari Jerman mengunjungi Batavia pada tahun 1680-an berpendapat bahwa tempat tersebut lebih indah dari Amsterdam (Susan Blackburn, dalam Christopher Fryke dan Christopher Schweitzer 2011: 26). Setelah kekuasaan Jepang, karena tidak setuju dengan kalimat Batavia yang masih Belanda kemudian diganti menjadi Jakarta dari kata Jayakarta. Jadi, secara historis kata Batavia mencangkup jangka waktu dari 1619 sampai 1942 atau pada masa kolonial.

Orang Betawi, menurut penelitian Milone dalam disertasinya Queen of the East: The Metamorphosis of a Colonial Capital, menyebutkan orang Betawi terbentuk dari beberapa kelompok etnik yang percampurannya dimulai sejak zaman kerajaan Sunda, Pajajaran, dan pengaruh Jawa yang ditandai dengan ekspansi Kerajaan Demak. Dalam hal fonologinya, bahasa orang Betawi kuat dipengaruhi oleh sistem fonologi jawa, Sunda dan Bali, sedangkan sistem morfologinya menunjukan sistem Melayu (C.Geertz 1960, dalam Lance Castle, 2007: 56).

Salah satu cirinya terdapat kepercayaan masyarakat Betawi kepada mahluk halus atau upacara (babarid; dalam bahasa lama) ${ }^{2}$. Arak-arakan adalah suatu upacara yang dilakukan pada waktu setelah panen, untuk bersyukur kepada Dewi Sri yang diyakini sebagai “Tuhan lokal" atau pemberi kesuburan. Masyarakat Betawi lama menyebut Ondel-ondel dalam bahasa Melayu adalah Kundil artinya kembang kertas, ketika Ondel-ondel mendapatkan ornamen kembang kertas nama Barongan tidak digunakan lagi dan menjadi Ondel-ondel (wawancara Ridwan Saidi 2011). Gambaran tentang mitologi itu di bentuk menjadi Ondel-ondel dengan konsep membawa pergi setan (roh-roh jahat) dari ladang persawahan untuk keluar dari area itu. Pada mulanya musik untuk arak-arakan biasanya selalu mengulang, tidak melodius yang bertujuan untuk mengakses alam lain. Misalnya, coba dengar kaum muslim pada saat zikir selalu mengungkapkan doa-doa dengan bahasa yang selalu mengulang (wawancara, Ridwan Saidi 2011).

Analogi keberadaan Ondel-ondel terungkap dari tulisan W. Scot, seorang pedagang Inggris yang pada awal abad ke tujuh belas berada di Banten, yang dikutip oleh W. Fruin Mees dalam bukunya yang berjudul Geschiedenis Van Java, jilid Il yang intinya kurang lebih sebagai berikut :

Pada tahun 1605, iring-iringan Pangeran Jayakarta Wijayakrama untuk ikut merayakan pesta khitanan Pangeran Abdul Mafakhir yang tiga tahun sebelumnya dalam usia 7 tahun telah dinobatkan sebagai Sultan Banten menggantikan ayahandanya, Sultan Muhammad, yang wafatnya di Palembang, antara lain membawa boneka berbentuk raksasa ("een reus en een moster')tidak mustahil dengan boneka raksasa itu adalah Ondel-ondel, yang pada zaman dahulu lazim dianggap perwujudan Danyang Desa, penolak mala petaka.(Th.Pegeaud, 1932:306, dalam Ruchiat 2003:158).

Pernyataan kemunculan Ondel-onde/ dialami juga oleh seorang asal Amerika bernama E.R. Schidmore yang datang di Batavia pada penghujung abad ke 19, melaporkan dalam bukunya, "Java, The Garden of The East', tentang adanya pertunjukan seni di Betawi berupa tarian-tarian di jalanan. Schidmore tidak menyebut secara jelas apa jenis tarian yang bermain di jalanan itu. Jakob Sumardjo (2007:25) menjelaskan bahwa seni pertunjukan Indonesia, seperti pertunjukan rakyat masih memiliki sifat transenden.

Bentuk dan struktur keseluruhan Ondel-ondel pada tahun 1910 berukuran besar masih terlihat sepintas seperti boneka potehi yang ada di Cina. Jika menurut Susan Blackburn Ondel-onde/ dipentaskan pada acara keagamaan. Nilai keindahan Ondel-ondel tidak semata-mata dihasilkan berdasarkan pertimbangan konsep yang serba rasional, tetapi pada pemikiran spiritual yang menghasilkan seni perlambangan sesuai dengan peradaban agama (Wiyoso, 1996, dalam, Dharsono, 2007:36).

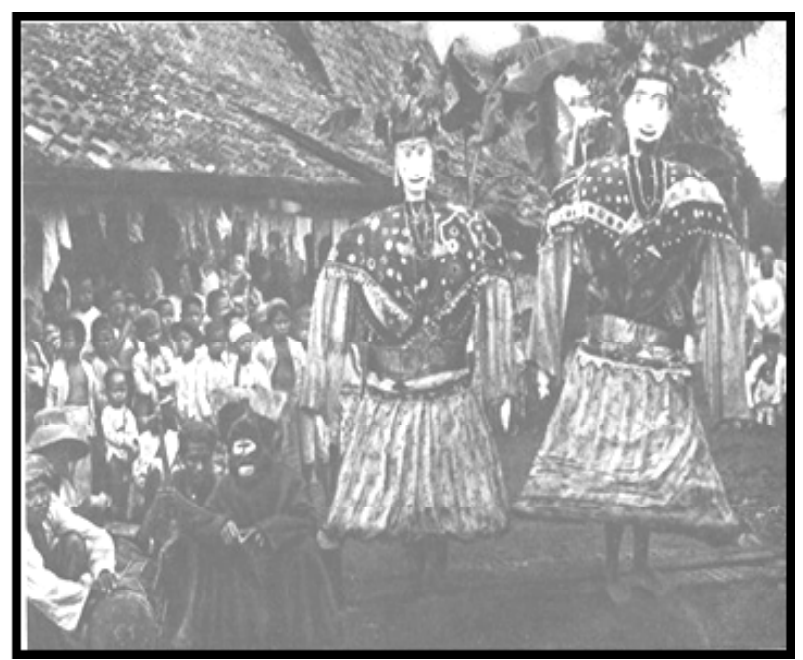

Gambar 1: Diduga Ondel-ondel sebagai tontonan masyarakat Tahun 1910, (Foto: H.J.de Graff, 1970,

Batavia in Oude Ansichten, Zaltbommel, Eropese Bibliotheek dalam Susan Blackburn, 2012:91. Repro Supriyanto, 2015). 


\section{GEELR Jumal sori buatya}

Analogi temuan keberadaan bentuk Ondelondel yang ditemukan di Hotel des Indies ${ }^{3}$ pada tahun 1923 dikaitkan dengan Motif topeng dengan wajah raksasa dalam seni dekoratif Jawa-Hindu disebut kala atau kirttimukha yang berarti ubahan bentuk (metamorfosa) menjadi wujud muka raksasa (Bosch, 1948:37-39, dalam, Wiyoso Yudoseputro, 2008:74). Tanda-tanda perlambangan pada hiasan mahkota segitiga keatas dijelaskan sebagai slempang (upawita) dan dibelakang kepala (prabha) yang biasa disebut orang Betawi adalah kembang kelapa. Atribut wajah Ondel-onde/ raksasa, seperti gigi yang menyeringai dengan taringnya serta dari mulut dengan tambahan dangastra pada dahi membentuk segitiga keatas, unsur-unsur ini semua menambahkan nilai magis pada wajah raksasa penjaga yang diyakini masyarakat masa lalu (I Nyoman Tusan dan Wiyoso Yudoseputro 1991: 27).

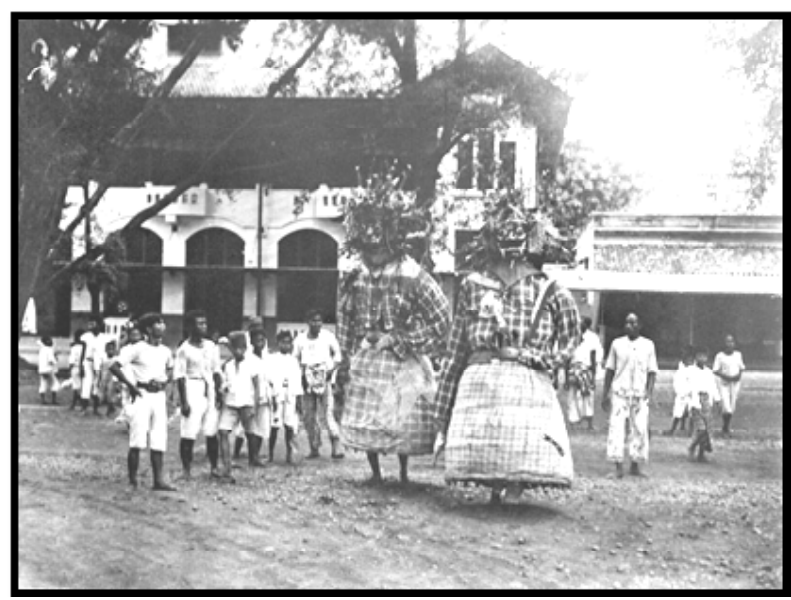

Gambar 2: Ondel-ondel pada pembukaan Hotel Des Indes, Batavia 1923 (Foto: http:// jakartapedia.bpadjakarta.net/index.php/ SejarahOndel-OndelBetawi. Repro Supriyanto. 2015)

Dugaan bukti foto ini adalah sepasang Ondelondel yang di tempatkan di depan gedung Keberadaan artefak foto ini sangat penting dapat membantu kita untuk melihat sedikit gambaran singkat tentang apa saja dalam suasana itu, diciptakan dan dikerjakan oleh suatu masyarakat dari sebuah kebudayaan tertentu pada jamanya (Alo Liliweri, 2014: 358). Bisa diamati pada gambar di atas ada beberapa benda yang menjulur menyerupai kembang kelapa (ronce-ronce) yang ditancapkan dengan tiang terlihat dipegang oleh dua orang anak). Tetapi diduga itu adalah perayaan sunatan/khitanan karena terdapat tempat duduk (singasana) dimana tempat itu untuk diduduki si pengantin sunat.
Ondel-ondel pernah digunakan sebagai peresmian pembangunan gedung Museum Mandiri yang berseberangan dengan Stasiun Kota. Dilakukan dengan prosesi penanaman kepala kerbau sebagai pertanda dimulainya pembangun gedung Museum Mandiri (Factorij). Rudolf Otto, semua sistem religi, kepercayaan dan agama di dunia berpusat kepada suatu konsep tentang hal yang dianggap gaib (mysterium) yang dianggap maha dasyat, maha keramat (sacer) oleh manusia (Koentjaraningrat, 2007:65). Upacara prosesi pemotongan kepala kerbau (korban) dilakukan untuk penghormatan terhadap mahluk yang gaib (Van Peursen, 1976:38).

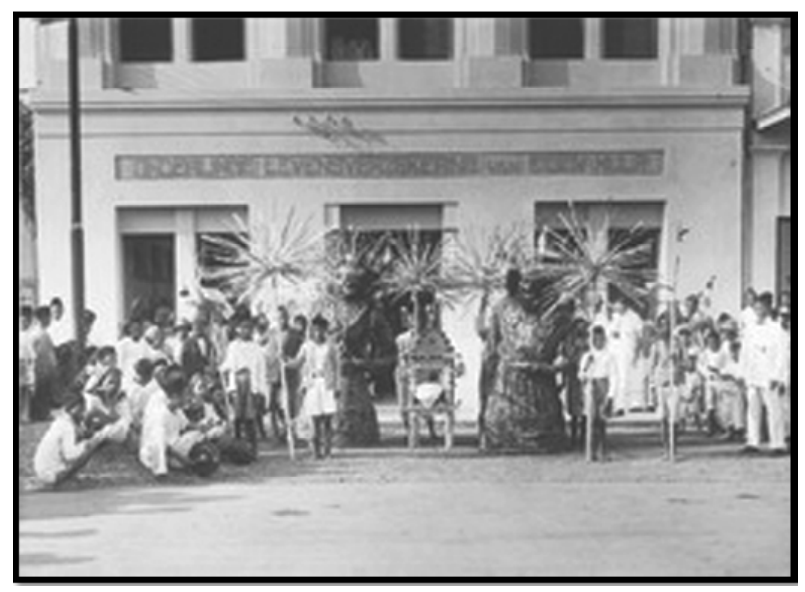

Gambar 3: Diduga Ondel-ondel sebagai upacara sunatan/ khitanan.

(Foto. Sumber dari www.pinterest.comhttp//ondelondel.com, Repro Supriyanto, 2015)

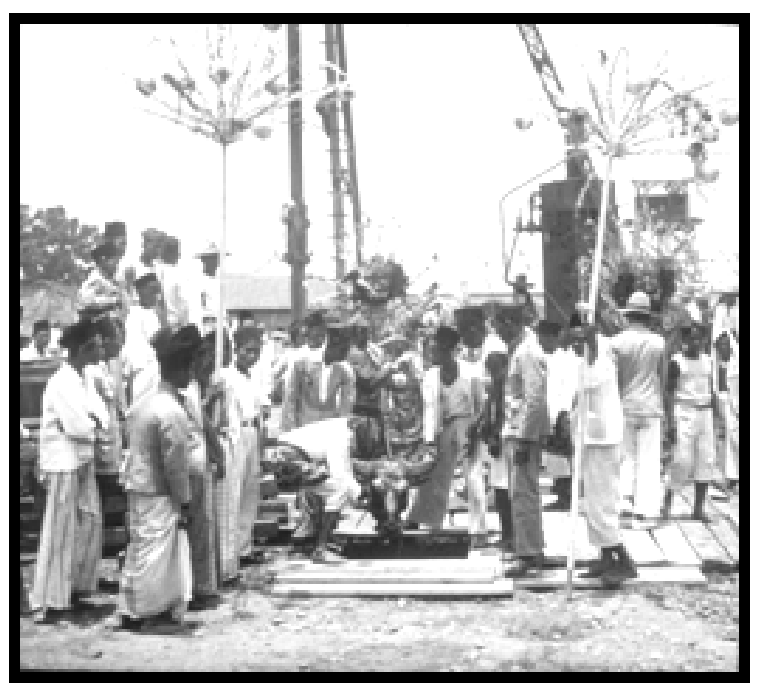

Gambar 4: Prosesi penanaman kepala kerbau dan ritual Ondel-onde/pada pembangunan Museum mandiri (Factorij).(Foto: Ariyanto Subarsah (Arsip dokumentasi AMRO/Museum Mandiri), repro Supriyanto 2016) 


\section{Bentuk dan Pemaknaan Ondel-ondel}

Nilai seni merupakan khayalan benda dan peristiwa yang biasanya menimbulkan kenikmatan dan kesenangan (SD Humardani, 1980:45). Bentuk Ondel ondel yang menyenangkan adalah bentuk yang dapat memberikan konsumsi batin manusia secara utuh, dan perasaan keindahan dapat menangkap harmoni bentuk yang disajikan lewat sensitivitasnya (Dharsono, 2007:31). Ondel-ondel merupakan bagian aktivitas masyarakat Betawi, artinya kesenian tersebut menjadi salah satu sarana hiburan bagi mereka, serta sebagian selingan dari pekerjaan rutinitasnya.

Ada beberapa sanggar dan pelaku seni yang berkecimpung untuk melestarikan kesenian Ondelondel. Jenis dari bentuk Ondel-ondelsendiri biasanya milik koleksi dari sanggar itu sendiri atau grup sanggar. Secara karakteristiknya memang selalu ada perbedaan dari gaya, warna dan bahan. Dari jenis dan gaya tersebut di antaranya dari sanggar Zein pimpinan Khamal yang berlokasi di Utan Kayu, Matraman Jakarta Timur, Sanggar Betawi Utan Panjang yang berlokasi di Kemayoran Jakarta Pusat, Ondel-ondel koleksi Museum wayang Jakarta Barat, Ondel-ondel milik koleksi Pahaja dan Ondel-onde/koleksi Museum Tekstil Jakarta Barat.

Pada karya Ondel-ondel tersebut akan di bahas dengan menggunakan teori estetika De Witt $\mathrm{H}$. Parker, dalam bukunya The Analysis of Art. Menjelaskan ciri-ciri umum bentuk estetis menjadi enam yaitu: (1). Asas Kesatuan Utuh. (The principle of Organic unity), (2). Asas Tema (The principle of theme), (3). Asas Variasi Menurut Tema (The principle of thematic), (4). Asas Keseimbangan (The principle of balance), (5). Asas Perkembangan (The principle of evolution), (6). Asas Tatajenjang (The principle of hirarchy), (The Liang Gie, 1976:48).

Analisis yang digunakan adalah pendekatan interprestasi, yaitu menginterpretasi karya seni berdasar sudut pandang pengamat, baik dari segi kesamaan pengalaman, sudut pandang, unsur keindahan, atau pengetahuan pengamat. Seni adalah pengalaman bentuk suatu medium sense yang sangat mengikat dan susunan secara bentuk diwujudkan untuk komunikasi secara perenungan (SD Humardani, 1980:74-75).

\section{Karya Ondel-ondel 1}

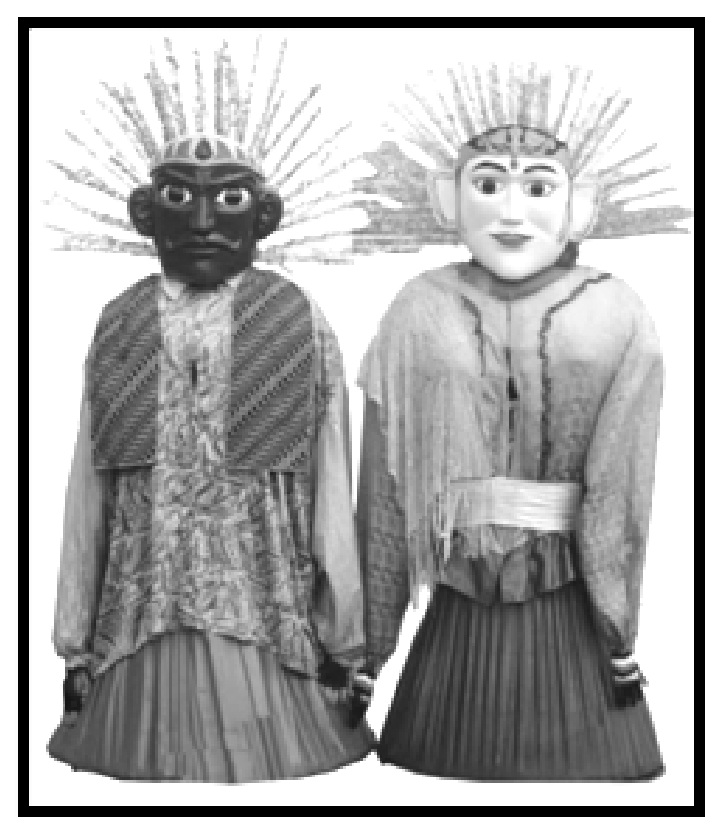

Gambar 5: Koleksi Ondel-ondel milik Sanggar Bintang Kejora

(foto : Supriyanto 2015)

Asas kesatuan keutuhan pada struktur Ondelondel berhubungan dengan bagian-bagian yang tampak yaitu terdapat pada kepala membentuk (wajah/ topeng dengan mahkota, ronce-ronce dan terdapat rambut di belakangnya terbuat dari ijuk/serabut kelapa), badan, tangan dan kaki. Pada tangan tidak ada kerangka melainkan hanya tali yang diikatkan dari pundak ke bagian telapak tangan yang terbuat dari sarung tangan yang diisi dengan kapas. Bagian badan dan tangan menyatu secara struktur menjadi satu kesatuan yang utuh. Warna laki-laki lebih dominan gelap merupakan keselerasan yang dinamik dipadukan dengan warna perempuan yang dominan warna terang menjadikan satu kesatuan dari prinsip Ondel-ondel.

Asas tema merupakan filosofi yang dipercaya oleh masyarakat Betawi sebagai simbol nenek moyang yang menjaga anak cucu yang masih hidup. Ondel-ondel selalu berpasangan melambangkan bahwa manusia selalu berpasangan dalam kehidupan. Laki-laki dan perempuan dalam masyarakat Betawi bermakna bahwa setiap pasangan tersebut mempunyai kedudukan yang sama, mencintai dan melestarikan. Wujud Ondel-onde/ laki-laki menunjukan perwatakan yang garang dan sadis. Kumis yang melintang tebal mencerminkan pada sosok si Jampang sebagai pahlawan budaya Betawi yang 


\section{GE[AR Jumal sori Budsya}

pemberani. Pakaian yang dikenakan oleh sepasang Ondel-ondel merupakan perlambangan jiwa sebagai identitas masyarakat Betawi yang selalu berlengan panjang.

Asas variasi menurut tema sebagai arahan atau menunjukan keBetawianya secara pengakuan untuk di legitimasi. Secara tema menutupi kepala dengan peci dan sarung kemudian mahkota dengan selendang merupakan cerminan identitas Betawi yang identik dengan islam. Sarung yang biasanya bermotif kotak-kotak namun, sebagai asas variasi sarung bermotif batik itu selain memiliki fungsi sebagai selimut atau sholat juga bisa digunakan sebagai senjata tradisional Betawi.

Asas keseimbangan, Keseimbangan pada bagian kembang ronce-ronce merupakan pengulangan unsur-unsur yang membentuk repitisi yang estetik. Dimensi mahkota yang seimbang antara keduanya memiliki tekstur yang berbeda namun memiliki kesamaan nilai dengan komposisi relief yang berbeda. Warna pada wajah menghadirkan keselarasan yang dinamik antara warna merah gelap di padu dengan warna putih yang terang menimbulkan kesan harmonis. Keseimbangan informal di lihat dari sarung yang melingkar di leher dan selendang yang di sampirkan di pundak tangan bagian kanan.

Asas perkembangan Asas perkembangan banyak di pengaruhi dari medium bahan (material) yang menyeluruh. Ornamen di kepala mengalami perkembangan bentuk motif relief yang selalu berubah-ubah diantara keduanya. Namun, dari semua bagian-bagian yang menentukan itu tidak menghilangkan makna yang terkandung di dalamnya. Hubungan antara antribut yang digunakan pada laki-laki yang melingkar di lehernya dan selendang yang disampirkan di pundak kanan masih identik terkait hubungannya dengan keislaman budaya yang beriman.

Asas tata jenjang merupakan tingkatantingkatan yang beraturan pada proporsi skala yang ditentukan. Perwatakan wajah laki-lakinya yang seram, kumis melintang, mata melotot dan perempuanya yang ramah.

\section{Karya Ondel-ondel 2}

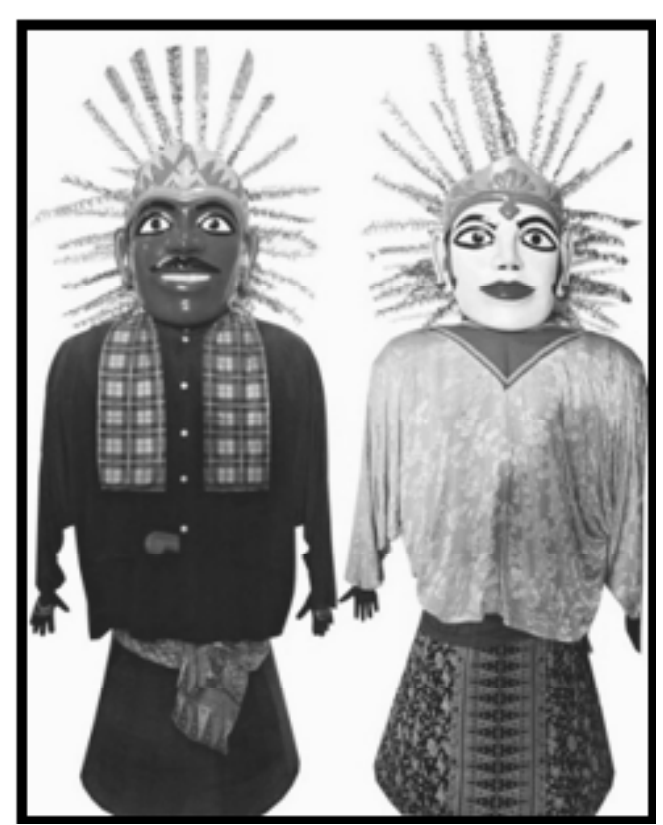

Gambar 6: Koleksi Ondel-ondel milik Museum Wayang Jakarta. (foto: Supriyanto, 2015)

Asas kesatuan terbentuk bagian kepala, badan, tangan dan tanpa kaki menyatu secara struktur menjadi satu kesatuan yang utuh. Susunan kombinasi yang meyesuaikan wujud keduanya tampak pada bagian-bagianya menyatu menjadi bentuk yang sempurna. Bentuk wajahnya terkesan harmonis dengan perpaduan warna yang kontras dengan relief sebagai atribut yang menjadi satu kesatuan dengan kepala. Badan yang menyatu dengan tangan menjadikan suatu komposisi susunan untuk memperkuat nilai keutuhan

Asas tema merupakan filosofi yang dipercaya oleh masyarakat Betawi sebagai simbol nenek moyang yang menjaga anak cucu yang masih hidup. Wujud Ondel-ondel laki-laki menunjukan perwatakan yang senyum menganga tetapi memiliki jiwa jawara atau kesatria. Dengan atribut golok berwana merah yang terselip di pinggang. Pakaian laki-laki paksi berwarna hitam dengan sarung yang melingkar dileher merupakan warna identitas sejarah gerakan perjuangan yang berani pada laki-laki Betawi. Pakaian perempuan dipilih warna cerah bermotif polos atau kembangkembang dengan ikat pinggang berwarna merah, pada bagian bawah mengenakan kain bermotif batik yang di senangi oleh kaum wanita Betawi.

Asas variasi menurut tema sebagai arahan atau menunjukan kebetawianya secara pengakuan untuk di legitimasi. Sarung bermotif kotak-kotak yang 
melingkar di leher, golok yang diselipkan di pinggang dan kain ditalikan di pinggang. Semua atribut itu merupakan ciri yang khas budaya Betawi. Kain segitiga berwarna biru melingkar di leher berfungsi sebagai pelindung atau menutupi bagian yang intim, bermakna sebagai bahwa perempuan Betawi bisa menjaga kewanitaanya dengan baik dan sopan.

Asas keseimbangan pada bagian kembang ronce-ronce merupakan pengulangan unsur-unsur yang membentuk repitisi yang estetik. Dimensi mahkota yang seimbang antara keduanya memiliki tekstur yang berbeda namun memiliki kesamaan nilai dengan komposisi relief yang berbeda. Keseimbangan informal di lihat dari sarung yang melingkar di leher dan kain segitiga melingkar di leher berwarna biru.

Asas perkembangan Asas perkembangan banyak di pengaruhi dari medium bahan (material) yang menyeluruh. Ornamen di kepala mengalami perkembangan bentuk motif relief yang selalu berubahrubah diantara keduanya. Namun, dari semua bagianbagian yang menentukan itu tidak menghilangkan makna yang terkandung di dalamnya.

Asas tata jenjang merupakan tingkatantingkatan yang beraturan pada proporsi skala yang ditentukan. Perwatakanya menunjukan wajah yang ramah, tercermin adanya masyarakat Betawi yang menghargai dari masyarakat pendatang yang menampung di Jakarta.

\section{Karya Ondel-ondel 3}

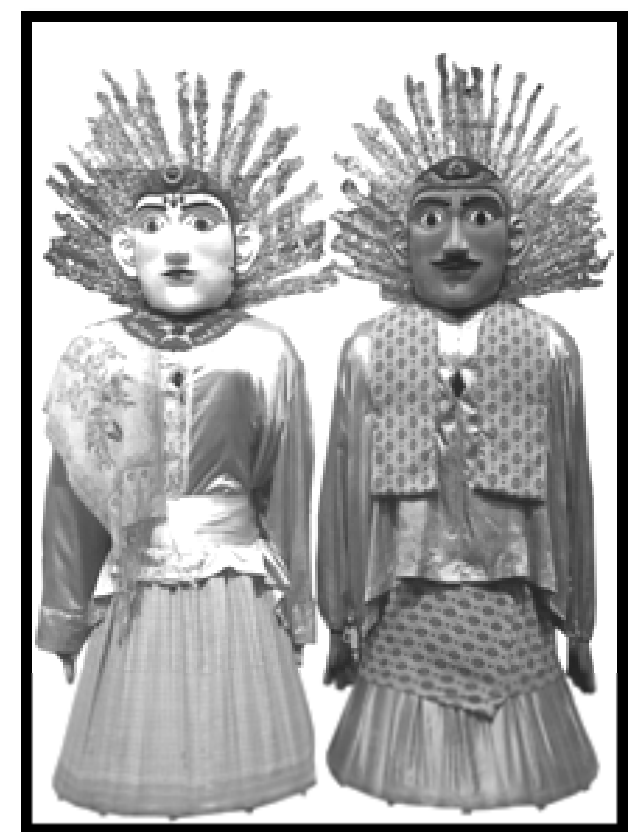

Gambar 7: Koleksi Ondel-onde/ milik sanggar Zein (Foto: Khamal 2011, repro Supriyanto 2015)
Asas kesatuan yang mengacu pada komposisi struktur bagian badan dan tangan menyatu secara struktur menjadi satu kesatuan yang utuh. Susunan kombinasi yang meyesuaikan wujud keduanya tampak pada bagian-bagianya menyatu menjadi bentuk yang sempurna.

Asas tema merupakan menunjukan penokohan untuk mencapai karakter yang realis yang penokohanya bukan merupakan jawara. Pakaian tertutup sampai leher, pada laki-lakinya memakai pakaian sandaria seperti baju koko dan pada perempuanya penambahan bahan kain berwarna merah berfungsi untuk menutupi aurat. Keduanya mempunyai makna sebagai orang Betawi yang berpegang teguh terhadap kaidah-kaidah islamnya untuk menjaga kepribadianya atau dirinya dari hawa nafsu.

Asas variasi menurut tema terlihat jelas pada bagian kain sarung bermotif bulat-bulat (polkadot) dan kain yang sama di ikatkan di pinggang. Selendang yang di sampirkan dilengan bagian kanan dengan motif kembang-kembang seperti jilbab penutup kepala dan selendang yang dililitka di pinggang. Terlihat jelas pada atribut yang di kenakan merupakan ciri khas budaya dengan keislaman yang berfungsi untuk kegunaan masing-masing. Sarung bermotif kotak-kotak yang melingkar di leher, golok yang diselipkan di pinggang dan kain ditalikan di pinggang. Semua atribut itu merupakan ciri yang khas budaya Betawi. Secara tema menutupi kepala dengan peci dan sarung kemudian mahkota dengan selendang merupakan cerminan identitas Betawi yang identik dengan islam. Dengan lipatan-lipatan yang sama besar sehingga sewaktu-waktu di butuhkan relatif lebih cepat dan mudah. Keanekawarnaan pada wajah Ondel-ondel tidaklah berwarna merah dan putih tetapi coklat dengan putih, hal ini akan menimbulkan kekacaubalauan. Tetapi variasi ini berdasarkan kesatuan dalam tema, tidak merubah wajah Ondel-onde/ dengan kekhasanya.

Asas keseimbangan wujud pada bentuk Ondel-ondel membentuk dimensi volume yang seimbang. Keseimbangan pada bagian kembang ronce-ronce merupakan pengulangan unsur-unsur yang membentuk repitisi yang estetik. Warna pada wajah menghadirkan keselarasan yang dinamik antara warna coklat yang natural di padu dengan warna putih yang terang menimbulkan kesan harmonis. Di bagian bawah terlihat draferi-draferi kain dengan dimensi volume bentuk melingkar menambah kesan tinggi menimbulkan gerakan gradasi yang menarik.

Asas perkembangan Asas perkembangan banyak di pengaruhi dari medium bahan (material) 


\section{GELAR Jumal sori buatsa}

yang menyeluruh. Ornamen di kepala mengalami perkembangan bentuk motif relief yang selalu berubahrubah diantara keduanya. Namun, dari semua bagianbagian yang menentukan itu tidak menghilangkan makna yang terkandung di dalamnya. Susunan pakaian laki-laki mempunyai gradasi untuk perpaduan dari interval kecil ke interval besar.

Asas tata jenjang merupakan tingkatantingkatan yang beraturan pada proporsi skala yang ditentukan. Wajah merah di padukan dengan warna putih yang menjadikan unsur pada perwatakan tersebut lebih menonjol. Keduanya saling melengkapi satu sama lain pada bagian-bagian yang di sebuatkan tersebut. Keduan figur Ondel-ondel mempunyai kedudukan terpenting yang laki-laki menampilkan sosok dari pahlawan Betawi dan perempuan menampilkan sosok perempuan yang secara mitos adalah Dewi Sri sebagai dewi kesuburan. Wajah terlihat sangat mirip hanya ada perbedaan waran wajah dan penambahan kumis yang menjadi peranan untuk membedakan antara laki-laki dan perempuan Betawi.

\section{Karya Ondel-ondel 4}

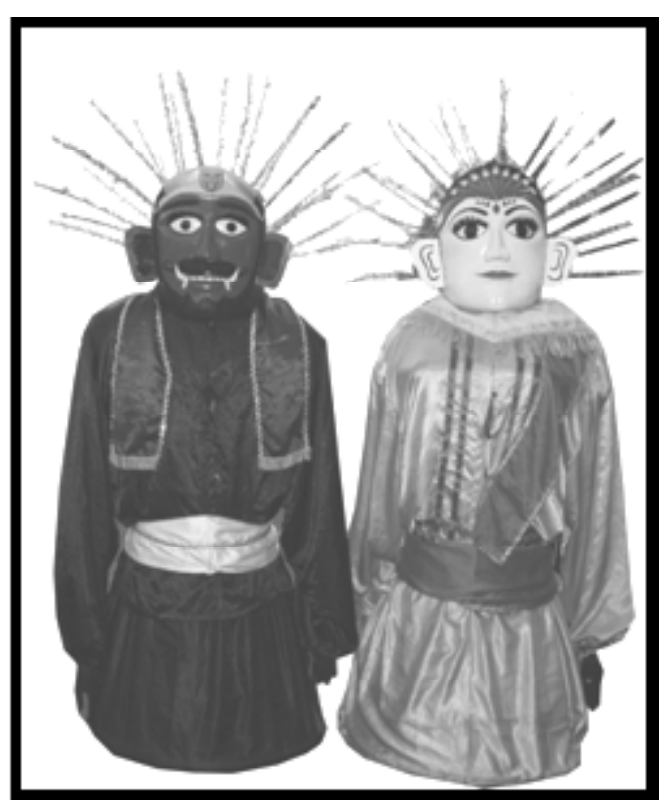

Gambar 8: Koleksi Ondel-ondel milik Pahaja (Foto: repro Supriyanto 2015)

Asas kesatuan pada bentuk keutuhan terjalin antara bagian-bagian yang lainya menyatu satu dengan yang lainya yaitu kembang ronce-ronce menyatu dengan kepala (dengan organ-organ manusia), menyatu dengan badan, tangan dan bagian bawah setengah kaki. Kepala yang mebentuk komposisi wajah manusia yang distilasi dan distorsi terlihat kaku dalam pembentukan kuping, mata melotot lebar dengan gigi yang menyeringai keluar.

Asas tema merupakan menunjukan penokohan untuk mencapai karakter dengan penggambaran manusia berkepala binatang. Berdampingan dengan bentuk perempuan yang cantik menambah keharmonisan sebagai pemanis dari kedua pasangan. Ondel-ondel selalu berpasangan melambangkan bahwa manusia selalu berpasangan dalam kehidupan. Tetapi menurut tama disini menampilakan Ondel-ondel untuk sebuah ritual bersih desa atau panen raya. Pada dasarnya konsep Ondelondel laki-lakinya lebih seram dari perempuanya baik itu, secara pakaian lebih dominan laki-laki berwarna gelap di bandingkan dengan warna perempuan. Pakaian tertutup sampai leher, pada laki-lakinya memakai pakaian paksi hitam-hitam seperti baju jawara dan pada perempuanya menggunakan bahan kain berwarna kuning keemasn berfungsi untuk menutupi aurat.

Asas variasi menurut tema terlihat dikepala nampak seperti mahkota mahkota yang disimbolkan sebagi penutup kepala merupakan cerminan identitas Betawi yang identik dengan islam. Kain berawarna ungu dengan hiasan tepian berwarna emas dan kain hijau mencolok merupakan perpaduan antara sorban dengan ikat pinggang berwarna hijau. Kehadiran atribut di bagian ini mencerminkan konsep etnis Betawi sebagai jawara dengan karakterisrik berpakaian pencak silat. Keanekawarnaan pada wajah Ondel-ondel tidaklah berwarna merah dan putih dengan gradasi kemerah-merahan menjadikan efek lembut dan alim.

Asas keseimbangan akan menimbulkan adanya kesan yang seimbang ditangkap oleh mata secara intensitas kekaryaan Ondel-ondel. misalnya dalam penyusunan bentuk mempengaruhi ukuran, wujud, warna, tekstur yang dihadirkan pada setiap bagian-bagian tertentu. Wujud pada bentuk Ondelondel membentuk dimensi volume yang seimbang.. Warna pada wajah menghadirkan keselarasan yang dinamik antara warna merah dengan hitam dan putih kecoklatan yang natural akan menimbulkan kesan harmonis. Keseimbangan informal di lihat dari surban yang melingkar di leher dan kain disampirkan di pundak bagian kanan melingkar di leher berwarna hijau.

Asas perkembangan Asas perkembangan banyak di pengaruhi dari medium bahan (material) yang menyeluruh. Ornamen di kepala mengalami perkembangan bentuk motif relief yang selalu berubahrubah diantara keduanya. Namun, dari semua bagianbagian yang menentukan itu tidak menghilangkan makna yang terkandung di dalamnya. 
Asas tata jenjang merupakan tingkatantingkatan yang beraturan pada proporsi skala yang ditentukan. Watak pada laki-laki yang meyerampak adalah konsep dari Ondel-ondel sebagi pendamping dari peremuannya yang diyakini Dewi Sri. Menjadikan kedua figur tersebut mempunyai kedudukan yang tidak bisa di pisahkan dan harus berdampingan.

\section{Karya Ondel-ondel 5}

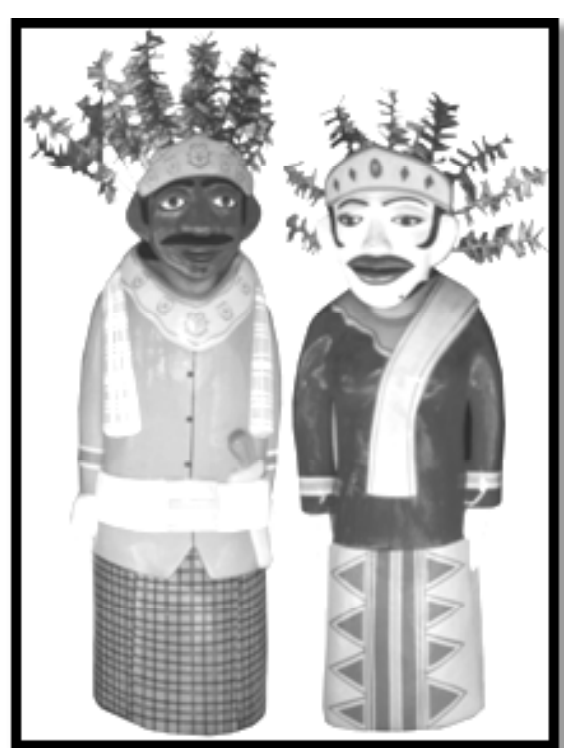

Gambar 9: Koleksi Ondel-ondel milik Museum Tekstil Jakarta

(Foto: Supriyanto 2015)

Asas kesatuan yang mencirikan suatu bagianbagian bentuk pengayaan perubahan organ tersebut mengalami distorsi stilisasi pada bagaian wajahnya terlihat cembung. Sorot mata yang sayu, kepala tanpa leher menyatu dengan kembang ronce-ronce yang mejulur ketas dengan garis yang beraturan menjadikan satu kesatuan nilai keutuhan dan seimbang. Susunan kombinasi yang meyesuaikan wujud keduanya tampak pada bagian-bagianya menyatu menjadi bentuk yang sempurna. Identitas dari kembang ronce-ronce masih menyatu dengan hiasan dikepalanya menambah kesan meriah dengan warna-warna primer. Susunan dari setiap bagian-bagian komposisinya merupakan pola umum dari tradisi Betawi. Seperti hiajau, merah, kuning, biru dan putih banyak dijumpai di dalam ornamen-ornamen tertentu yang sudah merupakan satu kebiasaan umum atau pola umum. Unsur warna hijau selalu di hadirkan dalam kehidupan orang Betawi bahwa dominan hijau melambangkan kesejukan dan kenyamanan identik dengan agama ilsma yang beriman. Penampilan dan bentuk visualnya yang menghibur
Asas tema merupakan bagian pakaian tertutup sampai leher, pada laki-lakinya memakai pakaian sandaria seperti baju koko dan pada perempuanya penambahan bahan kain berwarna hijau di bagian leher berfungsi untuk menutupi aurat. Pola motif pada setiap bagian figur perempuan kainya menonjolakan kain batik dan sarung pada pola bagian figur laki-lakinya bahwa batik merupakan kegemaran para kaum wanita Betawi dan kain sarung bermotif kotak-kotak merupakan identik oleh kaum laki-laki yang beriman. Ikat pinggang berwarna putih dan terselip golok sorenan yang berarti simpanan di pinggang merupakan gambaran cerminan simbolis budaya kepahlawanan Betawi. Selian itu juga bentuk dan karakter wajahnya menggambarkan kelucuan (lelucon), memang pada dasarnya orang Betawi tercermin dari banyolan/lawakan yang menghibur dalam sehari-hari.

Asas variasi menurut tema terlihat jelas pada atribut yang di kenakan merupakan ciri khas budaya dengan keislaman yang berfungsi untuk kegunaan masing-masing. Sarung bermotif kotak-kotak yang melingkar di leher, golok yang diselipkan di pinggang dan kain ditalikan di pinggang. Semua atribut itu merupakan ciri yang khas budaya Betawi. Secara tema menutupi kepala dengan peci dan sarung kemudian mahkota dengan selendang merupakan cerminan identitas Betawi yang identik dengan islam.

Asas keseimbangan akan menimbulkan kekontrasan warna yang ditimbukan keseimbangan masa terlihat warna laki-lakinya terkesan berat dari warna perempuanya. Kelengkapan dari atributnya menyerupai namun penempatnya yang berbeda pada bagian-bagian yang sama.

Asas perkembangan ekspresi yang dihadirkan terlihat laki-lakinya bermata sayu dengan tatapan mata bola mata keatas (kosong). Menafsirkan dari figur laki-lakinya yang sudah tua dengan penggunaan aspek shall yang melingkar tebal di leher dan ditambah dengan kain sarung. Asas ini orientasi bentuknya merupakan ide dari ncang ncing nyak babe (kakek, nenek, ibu dan bapak) pada orang BetawiOrnamen di kepala mengalami perkembangan bentuk motif relief yang selalu berubah-rubah diantara keduanya.

Asas tata jenjang merupakan tingkatantingkatan yang beraturan pada proporsi skala yang ditentukan. Perwatakan yang dihadirkan menujukan kelucuan atau banyolan yang menyimbolkan dari kehidupanya yang polos, apaadanya, dan selalu mengibur. 


\section{GEAR hamisanibuson}

\section{Kesimpulan}

Ondel-ondel adalah sebuah penggambaran budaya etnis Betawi disimbolkan sebagai nenek moyang yang menjaga anak cucunya. Perjalanan sejarah Ondel-ondel bermakna sebagai pengusir setan, ganguan roh halus dan di gunakan sebagai acara ritual bersih desa atau panen raya untuk menghormati Dewi Sri (Dewi kesuburan). Pengaruh dari budaya Hindu kerajaan Tarumanagara sangat lekat sekali, sekilas mirip dengan barongan (ogoh-ogoh) yang ada di Bali. Tetapi fungsi tersebut berubah menjadi sebuah hiburan dan perlengkapan yang wajib bagi masyarakat pendukungnya. Sebagai acara-acara yang dihadirkan dalam perwujudanya, melalui ekspresi yang berbeda namun pada kebutuhan yang sama. Bentuk yang dihadirkan beraneka ragam tergantung dari kebutuhan penggunanya. Kehadiran Ondel-ondel beragam makna yang disesuaikan dengan kehidupan masyarakat Betawi. Sekaligus sebagai acuan ekspresi yang menyangkut tentang kebudayaanya dalam berprilaku serta menonjolkan identitasnya sebagai orang Betawi.

\section{Catatan Akhir:}

1. Diantara orang-orang Indie atau maksudnya orang pribumi Nusantara, kota Batavia dikenal dengan nama Jacatra (Frieda Amran, 2012: 36-37).

2. Kepercayaan Betawi mempercayai arwah manusia, masih mempengaruhi kehidupan manusia yang masih hidup dan mereka juga mempercayai peran Dewi Sri pengendali kemakmuran persawahan dan Dewi Sadra (pada upacara nyadran) yang mengendalikan kemakmuran kelautan (Ridwan Saidi, 2002: 21)

3. Hotel des Indes tahun 1829-1971 merupakan salah satu ikon Batavia. Letaknya di ujung selatan Molenvliet west yang kini bernama Jl. Gajah Mada, Jakarta. Pada tahun 1949 namanya menjadi Hotel Duta Indonesia sekarang lebih dikenal dengan Duta Merlin, kemudian ditutup pada tahun 1962 oleh Soekarno karena bersaing dengan Hotel Indonesia.

\section{KEPUSTAKAAN}

Amran, Frida., Batavia (kisah kapten Woodes Rogers dan Dr. Strehler), Jakarta: Pt. Kompas Media Nusantara, 2012.

Blackburn, Susan., Jakarta Sejarah 400 Tahun, Jakarta: Masup Jakarta, 2012.

Chaer, Abdul., Betawi Tempo Doeloe, Menelusuri Sejarah Kebudayaan Betawi, Jakarata: Masup jakarta, 2015.

Kartika, Dharsono Sony., Estetika Nusantara, Bandung: Rekayasa Sains, 2007.

Liang Gie, The., Garis Besar Estetik (Filsafat Keindahan), Yogyakarta: Penerbit Karya 1976.

Ruchiat, Rachmat,. Asal usul nama tempat di Jakarta. Jakarta: Masup, 2012.

Parker, DeWitt H,. Dasar - Dasar Estetik. Terj. SD. Humardani, Surakarta: Akademi Seni Karawitan Indonesia (ASKI), 1979/1980.

Saidi, Ridwan., Babad Tanah Betawi, Jakarta: PT. Gria Media Prima, 2002.

Sumardjo, Jakob., Filsafat Seni, Bandung: ITB, 2007.

Toekio M, Soegeng., Seni Kita, makalah Seni Rupa, Surakarta, 2000.

Sedyawati, Edi, et al., Sejarah Kebudayaan Indonesia (Seni Pertunjukan dan Seni Media), Jakarta: Rajawali Pers, 2009.

Yudoseputro, Wiyoso., Jejak-Jejak Tradisi Bahasa Rupa Indonesia Lama, Jakarta: Yayasan Seni Visual Indonesia (YSVI), 2008. 


\title{
HUBUNGAN EKSPRESI PENUANGAN TARI BEDHAYA DENGAN KOREOGRAFI BEDHAYASARPARODRA SUSUNAN SARYUNI PADMININGSIH
}

\author{
Ryndhu Puspita Lokanantasari \\ Program Pascasarjana \\ Institut Seni Indonesia Surakarta \\ Jl. Ki Hadjar Dewantara No. 19 Kentingan, Jebres, Surakarta, 57126 \\ Slamet \\ ISI Surakarta
}

\begin{abstract}
ABSTRAK
Tari Bedhaya Sarpa Rodra merupakan karya tari model bedhaya yang diciptakan di luar istana. Tari ini menggambarkan keserakahan manusia yang diwujudkan pada tokoh Sarpakenaka. Sajian koreografinya menghadirkan keunikan terutama pada gerak dan musik tarinya. Untuk itu, perlu dianalisis bentuk tari bedhaya dan proses pembentukan koreografinya dengan pisau analisis konsep bentuk Suzanne K. Langer, konsep Hastasawanda, dan teori Effortshape, serta aspek koreografi kelompok Y. Sumandiyo Hadi.
\end{abstract}

Kata kunci: bedhaya, Bedhaya Sarpa Rodra.

\begin{abstract}
The dance Bedhaya Sarpa Rodra is a dance work of bedhaya model created outside the palace. The dance shows human greedmanifested in the figureSarpakenaka. The choreography presents uniqueness especially on the movement and the dance music. For the reason, the form of dance Bedhaya and the composing process of choreography need to be analyzed by the concept of form by Suzanne K. Langer, concept of Hastasawanda, and Effortshape theory, as well as aspect of group choreography by Y. Sumandiyo Hadi.
\end{abstract}

Keywords: Bedhaya, Bedhaya Sarpa Rodra.

\section{A. Pengantar}

Tari Bedhaya Sarpa Rodra merupakan salah satu karya tari model bedhaya yang diciptakan di luar istana. Tari Bedhaya Sarpa Rodra disusun oleh Saryuni Padminingsih pada tahun 2007 dan dipentaskan di Teater Kecil Institut Seni Indonesia Surakarta. Tari Bedhaya Sarpa Rodra ditarikan oleh tujuh penari putri dengan menggunakan rias paes dan busana dodot. Struktur sajiannya terbagi menjadi tiga bagian yaitu maju beksan, beksan, dan mundur beksan. Musik tarinya menggunakan gamelan Jawa yang dipadukan dengan gamelan Bali dan beberapa alat musik lainnya seperti jimbe, bedug, terbang, kenthongan, dan biola.

Sajian tari Bedhaya Sarpa Rodra berbeda dengan tari bedhaya tradisi yang masih kental dengan kaidah tari bedhaya di istana seperti pada penggunaan gerak yang cepat, kuat, kasar, rowa (besar) pada bagian tertentu, gerak-gerak sensual menggoyangkan pinggul, menggetarkan bahu, dan gerak-gerak badan yang meliuk-liuk, adanya ketidakterikatan ragam gerak antar penari dan keajegan irama baik ritme atau temponya. Selain itu, penari juga memperlihatkan adanya pengkarakteran tokoh melalui ekspresi tubuh maupun ekspresi wajahnya. Hal ini jarang ditemukan pada karya tari model bedhaya lainnya.

Begitu juga dengan mendengar musik tarinya, pada bagian vokal menggunakan syair dengan dua bahasa yaitu bahasa Jawa dan Indonesia, adanya sebuah percakapan yang dilakukan oleh pemain musik dan terdapat bagian tertentu yang tidak menghadirkan tabuhan musik atau dapat dikatakan musiknya berhenti sementara, bagian tertentu tidak seirama dengan sajian gerak tarinya. Artinya ada pengkontrasan irama di antara keduanya. Seperti pada bagian tengah sajian, menampilkan gerak- gerak yang energik tetapi alat musik tidak dimainkan melainkan adanya percakapan antara pemusik. Menuju akhir sajian juga ditampilkan irama musik yang cepat sedangkan penari bergerak dengan irama pelan yang ajeg. 